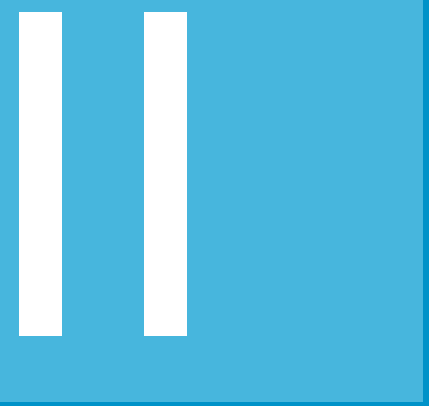

\title{
La educación adventista y su razón de ser
}

Adventist education and its reason for being

Universidad Peruana Unión, Perú

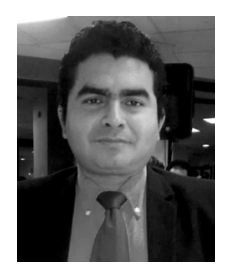

\section{Oscar Mendoza Orbegoso}

Bachiller en Teología por la Universidad Peruana Unión. Ha publicado varios artículos tanto en revistas teológicas como en libros especializados. 


\section{Resumen}

El propósito de este artículo es abordar sobre la razón de ser que tiene el sistema educativo adventista y cuán relevante continúa siendo su visión apocalíptica. La Iglesia Adventista del Séptimo Día tiene múltiples desafíos, probablemente, el principal tenga que ver con el asunto de la iglesia; sobre todo, en relación a su visión apocalíptica. Este desafío es latente también en las instituciones educativas adventistas. A través del análisis documental se observa la apocalíptica bíblica y su relación con el sistema educativo adventista.

Palabras clave: Apocalíptica bíblica, educación adventista, mensajes de los tres ángeles, misión educativa.

\section{Abstract}

The biblical apocalyptic vision has given the Seventh-day Adventist Church identity and relevance; without it, Seventh-Day Adventism would'n be the same. However, in recent decades, many have denied or have had a passive attitude towards this vision, both at the level of church and educational institutions (including schools, colleges and universities). This allows us to reflect whether its functions as an educational system is being fulfilled, and how relevant the apocalyptic vision remains in the Adventist Education.

Keywords: Biblical apocalyptics, adventist education, three angels messages, Second coming. 


\section{Introducción}

La Iglesia Adventista del Séptimo Día (IASD) tiene múltiples desafíos, probablemente, el principal tenga que ver con el asunto de la comprensión conceptual sobre iglesia; sobre todo, en relación a su visión apocalíptica. Paradójicamente, varios están dudando de la identidad, la misión y el mensaje proféticos del adventismo (Martínez, 2002; Mendoza, 2012).

Este desafío es latente también en las instituciones educativas adventistas. Hay quienes desconocen su naturaleza, o la están objetando, o la están tratando de olvidar. Otros, aunque suene extraño, desconocen la visión profética de la educación adventista.

Esta situación permite abordar sobre la razón de ser que tiene el sistema educativo adventista y cuán relevante continúa siendo su visión apocalíptica. Se tratará sobre (1) la apocalíptica bíblica en el adventismo, (2) la apocalíptica bíblica en la educación adventista, (3) el propósito principal de la educación adventista y, finalmente, (4) se darán algunas sugerencias para cada institución.

\section{La apocalíptica bíblica en el adventismo}

El adventismo nació "impulsado por la reflexión escatológica” (Canale, 2002, p. 168), identificándose como el remanente del tiempo del fin de Apocalipsis 12:17, teniendo un mensaje - los Mensajes de los tres ángeles de Apocalipsis 14:6-12; cf. 10:11 (Orbegoso, 2013) y cumpliendo una misión - la de preparar a los seres humanos para la segunda venida de Cristo. Esto la convierte en una "denominación apocalíptica" (Fredericks, 1988, p. 363).

Esta perspectiva ya era sostenida por los pioneros adventistas. Por ejemplo, en 1847, Joseph Bates percibía que Dios tendría un pueblo en el tiempo del fin, el cual proclamaría los mensajes de los tres ángeles. Para él, aquel pueblo era el adventismo (Bates, 1847). Por su parte, White (2012, p. 131), también, identificó a la IASD como remanente:

Los adventistas del séptimo día han sido elegidos por Dios como pueblo particular, separado del mundo. Con el gran instrumento de la verdad, los ha sacado de la cantera del mundo y los ha relacionado consigo. Ha hecho de ellos representantes suyos, y los ha llamado a s sus embajadores durante esta última fase de la obra salvación.

Timm (2004, p. 274) menciona que "los adventistas del Séptimo Día poseían una profunda convicción de que Dios les había confiado los últimos 
mensajes de advertencia para ser proclamadas a todo el mundo antes de la segunda venida de Cristo". En palabras de Höschele (2013, p. 299) el adventismo fue "conceptualizado por sus fundadores como una entidad temporal, preparando a las personas para estar entre los fieles de Dios en el momento de la inminente segunda venida".

En 1957, con el libro Questions on Doctrine, la Iglesia continuó con tal identidad (Seventh Day Adventist, 1957, p. 196). Hoy en día,esto es explícito en el Tratado de Teología Adventista, LaRondelle (2009, p. 997): “Los Adventistas se ven a sí mismos como el cumplimiento de la profecía apocalíptica, un movimiento profético llamado a preparar a un pueblo en todas las partes de la Tierra para estar listo para la aparición de Cristo".

Esta visión apocalíptica bíblica constituye la razón de ser de la IASD, de tal manera que todas sus creencias y estilo de vida giran en torno a ella (Timm, 1995); ya sea en el área de mayordomía o publicaciones, esta visión está inmersa en la profesión de fe; a tal punto que si se perdiera, el adventismo dejaría de ser lo que es. Como expresa Rodríguez (2008, p. 427): "El pensamiento apocalíptico está tan afianzado en nuestra conciencia y nuestra identidad como iglesia que intentar librarse de él conlleva el riesgo de la existencia de este movimiento".

La apocalíptica bíblica le ha permitido al adventismo comprender correctamente la Escritura. Daniel y Apocalipsis son libros que revelan el plan de salvación como un proceso y registran cómo Dios ha estado dirigiendo la historia de la redención desde el inicio hasta su clímax, la segunda venida de Cristo; todo esto comprendiendo el marco del conflicto cósmico.

La Iglesia Adventista cree que Dios dirige la historia, guía a los seres humanos a la verdad y a la salvación, y presenta un mensaje de esperanza. Precisamente esto, desde sus inicios, le ha dado al adventismo identidad y propósito. Knight (2008, p. 7) comenta:

Es esta visión [apocalíptica] la que ha hecho de nosotros un pueblo. A largo plazo, la visión apocalíptica es lo único que nos mantiene como una iglesia viviente, dinámica y con significado. La mayor amenaza para el adventismo hoy es la pérdida de la visión apocalíptica. Cuando la visión se pierde, también se pierde la razón de ser del adventismo.

Por este motivo, la iglesia adventista debe permanecer dinámicamente con esta visión. Sin ella, la iglesia sería una religión o una secta evangélica más;perdería totalmente su relevancia.

El problema, no obstante, es que el adventismo está siendo desafiado. 
Como se mencionó, esta visión poco a poco se está perdiendo. Para Knight (2008, p. 62)

Hemos hecho bien nuestra labor a la hora de decir a las personas que somos como otros evangélicos (salvo en lo del sábado y algunas cositas más) que hemos olvidado quienes somos, hemos olvidado lo que nos hace únicos, hemos olvidado lo que da significado a nuestra existencia.

Según Timm (1995), "La centralidad del mensaje de los tres ángeles para la teología de los adventistas del séptimo día, es menos enfatizada hoy que en los primeros días del movimiento adventista". Algunos hasta han señalado que la visión apocalíptica no es bíblica, por tanto, se necesita reinterpretarla o, en el peor de los casos, olvidarla, priorizando únicamente el evangelio.

\section{La apocalíptica bíblica en la educación adventista}

El adventismo nació como un movimiento anti-educación. Como muchos padres adventistas de aquella época (s. XIX DC) esperaban y predicaban el regreso inminente de Cristo, la educación de sus hijos no era importante (Schwarz y Greenleaf, 2002; Knight, 2008). Aquellos adventistas:

Creían que el regreso de Jesús estaba muy cercano, y que todas las decisiones y las actividades de la vida cotidiana deberían estar pauteadas por esta perspectiva: Jesús regresará en breve. Por eso, a lo largo de proceso de desarrollo organizacional, la preocupación por el establecimiento de escuelas no era fundamental (Departamento de educación adventista, 2009, p. 19).

Esta actitud, sin embargo, fue rápidamente desafiada y motivada por la visión apocalíptica. Knight(1872, p. 168) señala: “No es demasiado enfatizar que fueron las necesidades de la misión apocalíptica a toda nación, pueblo y lengua lo que dio energía a los comienzos de la educación adventista en la década de 1870". Ellos pensaron que en las instituciones educativas, los alumnos serían preparados para conocer "las grandes verdades de relevancia para nuestro tiempo" (School Committee, 1872, p. 168).

El objetivo principal de la creación del sistema educativo adventista fue predicar los Mensajes de los tres ángeles. Este sistema nació únicamente como un instrumento para el cumplimiento de la misión profética. Como declara White $(1958$, p. 117,118). 
La influencia de estos mensajes [de los tres ángeles] ha ido profundizando y ampliando [...] poniendo en existencia las instituciones de aprendizaje, casas publicadoras e instituciones de salud; todos estos son los instrumentos de Dios que cooperan en la gran obra, representada por el primer, segundo y tercer ángeles que vuelan en medio del cielo para advertir a las habitantes del mundo que Cristo está viniendo otra vez con poder y gran gloria (White, 1958).

¿Cuáles son los objetivos de la educación adventista al proclamar estos tres mensajes? En primer lugar, preparar a niños y adolescentes para el reino eterno de Dios (Departamento de educación división sudamericana, p.18). Según LaRondelle (2009, p. 986), "el propósito claro de la triple amonestación de Apocalipsis 14:6-12 es preparar a los habitantes de la tierra para la segunda venida de Cristo (ver vv. 14-20)".Indiscutiblemente, comprender y practicar los mensajes angélicos permite a cada alumno conocer a Cristo, la salvación desde su santuario, sus planes -tanto presentes como futuros- y la promesa de morar con Él para siempre. La apocalíptica bíblica revela a Cristo y sus obras en favor del alumno.

En segundo lugar, muchos estudiantes adventistas, por medio de este sistema, obrarían en conjunto con la iglesia en la proclamación de los mensajes angélicos. En otras palabras, en las instituciones no solo se formarían alumnos, sino también misioneros.

La dificultad, no obstante, es que esta visión se está perdiendo aun en las instituciones educativas adventistas. Por ejemplo, hay instituciones que se centran en la parte académica, dejando de lado la parte espiritual. Otras priorizan la parte espiritual y no se pone mucho énfasis en la parte académica. Hay varios casos que, si bien es cierto equilibran ambas partes, en lo que atañe a la consagración del alumnado y de los docentes, algunas veces se presenta y vive un estilo de vida cristiano subjetivo, distante de lo que registra la Palabra de Dios. Peor aún, y probablemente es más notorio, algunos de nuestros alumnos y profesores están viviendo como si Cristo no viniera en "cien mil millones de años". La expectativa y preparación para estos eventos no se están reflejando.

Un último problema, es que varios de los alumnos adventistas no están cumpliendo la misión profética; es más, posiblemente, desconocen el papel del adventismo y de sus colegios en el tiempo del fin. Al desconocer esta visión, no sorprende porqué muchas instituciones educativas adventistas, actualmente, están perdiendo su relevancia.

Anderson (2009, p. 51) comenta: "Debiéramos proclamar fervientemente el mensaje de los tres ángeles, quitar las capas de decepción de los ojos de la 
gente y al mismo tiempo hacer discípulos para Cristo que sean genuinos y maduros".

En conclusión, la apocalíptica no solo es la razón de ser del adventismo, también lo es de su sistema educativo. Knight (2008, p. 7) declara: "La educación adventista nació en la matriz de una visión apocalíptica, y cuando esa visión se pierde, también se pierde la necesidad genuina de la educación adventista". Asimismo enfatizó: "Un ministerio educativo adventista que ha perdido su influencia en la visión apocalíptica ha fallado, no solo parcialmente, sino totalmente" (Knight, 2010, p 56).

\section{El propósito principal de la educación adventista}

Paulien (2008, p. 299) comenta sobre la iglesia, que "había de desempeñar un papel primordial en la preparación del mundo para el pronto regreso de Jesús y ser motivada para llevar este mensaje al mundo en un breve período". En este sentido la educación adventista "es una de las maneras más efectivas de preparar a jóvenes para la segunda venida de Cristo" (Anderson, 2009 p.22).

El propósito de la educación adventista no es solo informar, tampoco es enseñar ética, mucho menos preparar profesionales competentes para este mundo. Por el contrario, su misión es preparar a estudiantes para el encuentro con su Creador y guiarlos a la salvación eterna en Cristo. Ellos deben comprender que, si bien es cierto existen hogares disfuncionales, todo el mal tendrá un fin; el sufrimiento y la muerte dejarán de existir, todo llanto y dolor terminarán (Ap 21:1-4). Por el contrario, el gozo, la felicidad y la paz serán instaurados en el reino mesiánico y eterno de Jesucristo (Is 65:17-25). Para esta labor se establecieron las instituciones adventistas, para dar a conocer un futuro mejor para los alumnos y sus respectivas familias. Los profesores son llamados para "presentar la doctrina de la vida eterna como una realidad tanto presente como futura" (Fredericks, 1988, p. 364). Knight (2010, p 54) indica:

El adventismo ha sido llamado para predicar a un mundo perdido la última esperanza, que por comparación palidece todas las demás. El objetivo central del adventismo es predicar esa última esperanza. Y la razón principal del establecimiento de las escuelas adventistas es preparar a las personas para ese evento y para la tarea de difundir las buenas nuevas del regreso del Salvador. 
Oscar Mendoza Orbegoso

Anderson (2009, p. 51) es más enfático al hablar sobre la misión del sistema educativo adventista:

Somos llamados a conocer y dar a conocer a Cristo, para preparar el mundo para la segunda venida a través de la obediencia a la gran comisión y la proclamación del mensaje de los tres ángeles. Ese es nuestro principal llamado y cualquier cosa inferior representa una salida suicida de nuestra razón de ser.

Para que este propósito se cumpla, cada institución necesita reflexionar cuál es su razón de ser y cuál es su compromiso para con Dios, la iglesia, el estudiante y la familia. Si bien es cierto a cada colegio adventista se le exige preparar a sus alumnos para ingresar a una universidad-ya sea estatal o privada- su prioridad es formar alumnos con un carácter semejante al de Cristo y que estos lleguen a cumplir la misión.

Cristo no vendrá por ingenieros competentes o médicos preparados, mucho menos por administradores o contadores capacitados. Él regresará por aquellos que son suyos, sus hijos.

\section{Sugerencias a cada institución adventista}

Con el propósito de enfatizar la visión apocalíptica del adventismo en cada una de las instituciones, se da algunas recomendaciones:

(1) La Asociaciones Educativas adventistas necesitan ser promotoras de esta visión. Los líderes y sus colaboradores deben proponer una lista de actividades que ayuden a cumplir esta visión. Cualquier plan educativo que no tenga en cuenta la visión apocalíptica, no llegará a ser relevante para la institución.

(2) Cada docente necesita, al igual que aquellos que sirven en la Asociación Educativa, conocer más sobre la temática relacionada a: (a) El santuario, (b) Daniel y Apocalipsis, y (c) El conflicto cósmico. Este es el ABC de todo profesor y pastor adventista.

(3) Los profesores, al conocer más sobre esta temática, pueden transmitirlo a sus estudiantes a través de las reflexiones diarias, ya sea en las aulas o a través del convivir diario con el alumno.

(4) Se recomienda exponer temas que no solo se relacione con el diario vivir de todo joven (temas como el enamoramiento, sexo, autoestima, música, redes sociales, etc.), sino también relacionadas con el conocimiento de Cristo, su ley, su Palabra, juicio investigador, santuario, etc. Recuérdese que los 
pioneros adventistas, establecieron las instituciones educativas con la intención de que los alumnos reciban instrucción doctrinal y profética.

(5) Desarrollar lecturas relacionadas al libro "El gran conflicto" de Elena de White.

(6) Es bueno que los docentes consideren las verdades distintivas del adventismo en el momento de exponer la asignatura en el aula.

\section{Conclusión}

Se ha desarrollado un análisis reflexivo en torno a la apocalíptica bíblica en el adventismo, la apocalíptica bíblica en la educación adventista y el propósito principal de la educación adventista

Knight (2010, p. 9) recalca:

La educación adventista es importante solamente si es verdaderamente adventista. Si no lo es, puede ser vista como una alternativa a otros sistemas de educación, pero no necesariamente la más importante, y por lo tanto no digna de mucho sacrificio financiero.

Es un verdadero reto cumplir la misión como sistema educativo adventista.

Oscar Mendoza Orbegoso

Universidad Peruana Unión, Perú

email: oscarsmorbegoso@gmail.com

Recibido: 15 de setiembre de 2015 Aceptado: 15 de diciembre de 2015

\section{Referencias}

Anderson, S. (2009). How to Kill Adventist Education and How to Give It a Fighting Chance! Hagerstown, MD: Review and Herald.

Bates, J. (1847). Second Advent way Marks and High Heaps, or, A Connected View of the Fulfilment of Prophecy, by God's Peculiar People from the Year 1840 to 1847. New Bedford, MA: Benjamin Lindsey.

Bates, J. (1847). The Seventh Day Sabbath: A Perpetual Sign, 2d rev. and enl, ed. New Bedford, MA: Benjamin Lindsey, 1847. 


\section{Oscar Mendoza Orbegoso}

Canale, F. (2002). Hermenéutica, teología y remanente, en Pensar la iglesia hoy: Hacia una eclesiología adventista, eds. Gerald Klingbeil, Martin G. Klingbeil y Miguel Ángel Núñez. Entre Ríos, Argentina: Universidad Adventista del Plata.

Departamento de Educación de la División Sudamericana de la Iglesia Adventista del Séptimo Día. (2009). Pedagogía adventista: Versión revisada y actualizada, trad. Graciela López de Pizzuto. Buenos Aires: Asociación Casa Editora Sudamericana.

Fredericks, R. (1988). A Sequential Study of Revelation 1-14 Emphasizing the Judgment Motif: With Implications for Seventh-day Adventist Apocalyptic Pedagogy. PhD dissertation, Andrews University.

Höschele, S. (2013) The Remnant Concept in Early Adventism: From Apocalyptic Antisectarianism to an Eschatological Denominational Ecclesiology. Andrews University Seminary Studies AUSS 51(2) 299.

Knight, G. (2008). Nuestra iglesia: Momentos históricos decisivos, trads. Claudia Blath y Sergio V. Collins. Miami, FL: Asociación Publicadora Interamericana.

Knight, G. (2008). La educación adventista y la visión apocalíptica- parte I, Revista de Educación Adventista 27(7).

Knight, G. (2008). La visión apocalíptica y la castración del adventismo. Miami, FL: Asociación Publicadora Interamericana.

Knight, G. (2010). Redemptive Education [Part III]: Implications of Philosophy for Adventist Education. The Journal of Adventist Education, October-November 56.

Larondelle, H. (2009). Remanente y mensajes de los tres ángeles, en Tratado de teología adventista, ed. Raoul Dederen, trads. Aldo Orrego, et al. Buenos Aires: Asociación Casa Editora Sudamericana.

Martínez, C. (2002). El concepto del remanente en la Iglesia Adventista del Séptimo Día: Razones subyacentes en el debate contemporáneo. Tesis doctoral no publicada. Universidad Adventista del Plata.

Mendoza, O. (2012). El remanente en Apocalipsis 12 al 14 y la Iglesia Adventista del Séptimo Día. Didajé 1(1), 75-78.

Paulien, J. (2008). La hermenéutica de la apocalíptica bíblica. en Entendiendo las sagradas Escrituras: Un enfoque adventista, ed. George Reid. Miami, FL: Asociación Publicadora Interamericana.

Rodríguez, A. (2008). Los adventistas y el método histórico-crítico, en Entendiendo las sagradas Escrituras: Un enfoque adventista, ed. George Reid. Miami, FL: Asociación Publicadora Interamericana.

School Committee (1872).The Proposed School, Review and Herald, 07 de mayo de 1872.

Schwarz, R y Greenleaf, F. (2002). Portadores de luz: Historia de la Iglesia Adventista del Séptimo Día, trad. Rolando Itin y Tulio Peverini. Buenos Aires: Asociación Casa Editora Sudamericana.

Seventh- Day Adventists (1957). Answer: Questions on Doctrine. Washington, DC: Review and Herald.

Timm, A. (1995). The Sanctuary and the Three Angels' Messages, 1844-1863: Integrating Factors in the Development of Seventh-day Adventist Doctrines. PhD dissertation, Andrews University.

Timm, A. (2004). Escatologia Adventista do Séptimo Dia, 1844-2004. en O Futuro. Sao Paulo: Casa Publicadora Brasileira.

White, E. (1958). Selected Messages, 03 vols. Washington, DC: Review and Herald, 2:117-118.

White, E. (2012). Testimonios, vol. 3. Washington, DC: White Estate. 